\title{
Improving the Ability of Public Service of Local Government in Chinese Minority Areas
}

\author{
Yuan Fang \\ School of Public Management (SPM), Yunnan University of Finance and Economics, P. R. China, \\ 2513020416@qq.com
}

\begin{abstract}
In recent years, local government in Chinese minority areas make great effort to improve the quality of public service, despite many achievements have been scored, there is still a wide gap between the eastern coastal regions. With in-depth development of regional integration of administrative work in China, local governments need to establish a scientific development concept in minority areas, strengthen the consciousness of public service, establish a sound legal system, and strengthen the coordination of communication across the administrative areas. Play its comparative advantage of local government at all levels in minority areas, will be conducive to improve the level of public service capacity building, eventually realize the sustainable development of ethnic areas.
\end{abstract}

Keywords: regional administrative integration; National regions; Local government; the public service ability

\section{Introduction}

Local governments in Chinese minority areas are an important part of the country's government system. The implementations of local government public service function, are not only directly related to the stability of the political, economic and social development in national regions, but also affect the improvement of the national public service system and improve. Therefore, local government public service capacity building in minority areas is very urgent. To carry out the related research in the field of has extremely important theoretical and practical significance.

\section{The Basic Connotation of Public Service Ability of Local Government in Minority Areas}

The local government is an important part of a national political system, the former did not understand, cannot understand the latter. Every country has only one central government, there are multiple local governments. The local government is closely related to People's Daily life. The government's work is related to the diversity of geographic and social environment also.
For the definition of local government, the Chinese academic circles at present did not form a unified point of view. This paper defines the local government as the local administrative authorities at various levels, including the province (municipality directly under the central government, autonomous region), city (cities under separate state planning, prefecture) and county (county-level cities), villages and towns such as local government administrative organs at all levels.

In this article, national regions including China's Inner Mongolia autonomous region, guangxi zhuang autonomous region, Tibet autonomous region, xinjiang uygur autonomous region, ningxia hui autonomous region, the five ethnic autonomous regions, guizhou, yunnan, qinghai province, gansu and sichuan provinces such as five multi-ethnic province and other provinces of minority cadres in minority areas. Local governments in national regions is refers to the administrative authorities at all levels of local government.

Because the local government in a timely manner to know the accurate information of the public service demand in our region, so relative to the central 
government, can more effectively meet the needs of the public in time, realize the maximization of the efficiency of public goods and public service supply. In modern times, in both the nation-state and multiethnic country, the local government to fulfill their obligation to the corresponding public service function, provide a large amount of public goods and services. As a multi-ethnic country, China has a population of more than 100 million ethnic minorities, widely distributed in all over the country provinces and autonomous regions, and mainly in the western region and border areas. National autonomous areas land area accounted for more than $64 \%$ of the nation's total.

Perfect public service system of local government in national regions and the continuous improvement of service ability level, for the national overall sustainable development level of ascension plays an extremely important role. Scientific set of local government in minority nationality regions related functional departments of the management level of public service, and the corresponding function content, can help the central government to carry out and implement the spirit of public decision-making in a timely and effective manner. At the same time, through the collation of information and transfer, the central government can accurately understand the ethnic people of all ethnic groups for public service ideas and suggestions, the corresponding public decision-making and implementation methods to modify, improve the overall efficiency and level of national governance.

\section{The Practical Necessity of Strengthening Regional Cooperation}

Chinese government clearly put forward in the report of the Seventeenth National Congress, to break the boundaries of administrative divisions available, giving full play to local advantages, forming tight economic circle and the economic belt in the domestic area. To promote regional economic and administrative integration process, the development of regional cooperation has become the main direction of our country in the new period of socialist market economic construction and development, and become an important way for China to promote local economic construction and the reform of the administrative system development.

\subsection{To promote regional economic and administrative integration process}

The development of regional cooperation has become the main direction of our country in the new period of socialist market economic construction and development, and become an important way for China to promote local economic construction and the reform of the administrative system development. With the rapid development of China's socialist market economy, various regions according to their own advantage, directly participate in international and domestic competition and access to development resources. Extension and expansion of regional cooperation and development, especially the development of system to regional economic integration and the administrative integration based gradually mature, has gradually developed into a new breakthrough point to promote the coordinated development of various fields of the society in the new period of China.

This is the central macro-control policies, on the other hand is also a system of socialist market economy and an inevitable result of the development of their own continuous improvement.

The original limit rigid administrative division is gradually broken, make all kinds of public resources 
to achieve a free, effective flow through the benign competition and orderly in between and within regions, and greatly improve the efficiency and ability of local government departments at all levels to obtain and use the related resources. Therefore, local governments in national regions by strengthening the regional cooperation and promote regional integration, the supply of public goods and services can reasonable planning. Clear understanding their public service ability of gap will contribute to effective implementation of public service function and responsibility.

\subsection{Strengthening regional cooperation, promote} regional administrative integration

Which is beneficial to the construction of service government work, realize effective supply of public products and services and equitable distribution. In February, 2004, premier wen jiabao at the central party school "to set up and implement the scientific concept of development" research put forward the concept of "building a service-oriented government" .Regional cooperation development concept in the new period of development, regional administrative integration mode gradually mature, especially the relevant system establishment and the perfection of legal system, for the local governments in national regions to participate in the service oriented government construction provides a good opportunity. Under the mode of regional cooperation, the local governments in national regions only through establishing the image of its efficient, democratic and clean government, through public service consciousness and improve their level of public service ability, constantly attract and get their own development needs of various kinds of resources, and expand the space for the sustainable development of the region's future.
Along with the accelerating the pace of regional cooperation and service-oriented government construction work in the central and local governments at all levels further. Between the local governments in national regions and the central government in supplying public products and services in the field of cooperation is bound to more closely. This will promote housing, health care, education and other fields, the central macroeconomic regulation and control policy. Equal basic public services job objectives in ethnic minority areas will be effective to carry out and implement.

\section{Several Measures to Enhance the Level of Local} Government Public Service Capacity in Minority Areas

According to the above analysis, the author thinks that in the face of regional cooperation and the development of the regional administrative integration in the new period, should be mainly from the following several aspects.

\subsection{Change the idea of development}

The establishment of cooperation and win-win concept guidance, protection of local government public service ability in ethnic regions effectively enhance. Need different development pattern of different development idea. In the model of regional cooperation and development, the work of local government public service capacity construction in minority areas, to abandon the traditional administrative conservative and closed concept.

First of all, in the process of gradually achieved the integration of regional administration, the local government in order to establish the guiding ideology of win-win cooperation, actively participate in regional cooperation and abandon the narrow local 
protectionism. Second, local governments at all levels in national regions should establish balanced development concept, starting from the overall target of regional development, reasonable and efficient use of its own resources advantage, fully realize the complementary advantages. In this process, attention should be paid not only to the economic and social development level differences between different regions, but also pay special attention to the coordination development level of the minority areas. Third, the ultimate goal is to achieve social harmony, sustainable development of the cooperation between the region.

Therefore, the local government should always adhere to the people-oriented, pay attention to political, economic, cultural, social and natural environment, multi dimension and coordinated development of the principles and concepts. Underdeveloped economy in some ethnic minority areas, for a long time to realize the rapid development of regional economy, some local government's excessive exploitation of natural resources, not only caused a great waste of natural resources, and even cause an ecological disaster.

Therefore, dominated by the scientific outlook on development, sets up the concept of sustainable development, achieve mutual benefit is the basic premise of improving the ability of public service of local government in minority areas.

\subsection{Cultivate the public service consciousness,} clear local service-oriented government construction goal, building regional administrative integration development in national regions system platform.

Government departments play its function advantage, for the overall development of society in various fields in the area of building cooperation platform, will realize the rational flow of regional development of resources of all kinds of, optimal allocation and efficient utilization. Therefore, local government in minority areas should not only change the concept of cooperation and development, but also to enhance the awareness of public service. Combined with specific targets of service oriented government construction in this region, the local government administrative organs in national regions, we should cultivate the public service consciousness, arouse public service departments at all levels of subjective initiative and innovation consciousness, combined with the natural resources of ethnic areas and the advantages of the characteristics of national culture, to form the overall planning and target system of local government work. As mentioned earlier, the development of the regional administrative integration in the new period for the local service-oriented government construction provides a new opportunity. But we should clearly recognize that the regional administrative integration is not a simple process.

First, local governments in national regions must first to re-examine its own structure characteristics of the administrative organization system, combining the super-ministries reform work gradually expand, in the construction of local service-oriented government as the basic goal, adjust the structure of related institutions and functions, thus to improve the efficiency of public services. At the same time should also be through the establishment of complete cooperation consultation mechanism, such as regional development high-end, BBS and other forms to ensure that the cooperation between local governments in national regions is orderly and continuous.

Secondly, local governments should establish a correct concept of competition, realize the separation of government and enterprise, create good conditions 
for the development of the free flow of resources within the region.

Third, the district government departments in all localities should through the relevant system construction, build and perfect regional cooperation platform, through quality and efficient services, and create a good environment for the regional cooperation development, enhance comprehensive cooperation main body's own competitive advantage.

4.3. Establish regional cooperation in the legal system, to standardize the cooperation development main body behavior, ensure that the local government public service capacity building in national regions in accordance with the law.

Under the rule of law is the basic premise of maintaining social justice, safeguard the rights of citizens, but also the basic requirement of promoting the construction of a service-oriented government in the new period. Local government public service ability construction in national regions, must establish on the basis of the legal system of complete and mature. Rule by law is the basic principle and requirement of modern administration, especially in the region administration integration development model has been established and the continuous development of today. Local governments in national regions in the process of production and distribution of public goods, must always keep its decisionmaking, implementation and evaluation and supervision work is heavily into the regional cooperation of the standard system of rule by law.

The regional cooperation in the legal system, on the one hand, local governments at all levels can regulate ethnic areas in the overall regional development planning system within the framework of the orderly competition and cooperation. On the other hand, gradually improve relevant laws and regulations system, improve the level of regional cooperation under the rule of law, and promote local government public service capacity building in national regions to the rule of law and the regularization of the guarantee.

\section{References}

(1) H·B·Thorell. (1986). 'Networks: between Markets and Hierarchies'. 1986( 7) : pp. $37-51$

(2) Lance , Davis and Douglass North (1971). Institutional Change and America Economic Growth.Cambridge University Press, p. 10.

Tingwei Zhang (2006). From intercity competition to collaborative planning, the case of the Yangtze river delta region of China. Urban affairs review, Volume 42, $2006(1): p p 26-56$. 